\title{
BODY COMPOSITION ALTERATIONS, ENERGY EXPENDITURE AND FAT OXIDATION IN ELDERLY MALES SUFFERING FROM PROSTATE CANCER, PRE AND POST ORCHIECTOMY
}

\author{
Cristiana Reis, Sami Liberman, Antonio Carlos Pompeo, Miguel Srougi, \\ Alfredo Halpern, Wilson Jacob Filho
}

doi: $10.1590 / \mathbf{S 1 8 0 7 - 5 9 3 2 2 0 0 9 0 0 0 8 0 0 0 1 2}$

\begin{abstract}
Reis C, Liberman S, Pompeo AC, Srougi M, Halpern A, Filho WJ. Body composition alterations, energy expenditure and fat oxidation in elderly males suffering from prostate cancer, pre and post orchiectomy. Clinics. 2009;64(8):781-4.
\end{abstract}

INTRODUCTION: Testosterone is needed for normal male development, muscle strength, bone mineralization, hematopoietic function, and sexual and reproductive functions. The main purpose of androgen deprivation therapy in prostate cancer is to reduce tumor progression, but therapy is often accompanied by significant adverse effects.

OBJECTIVE: This study aimed to determine the effects of androgen deprivation therapy on body composition and resting metabolic rate in patients with prostate cancer.

PATIENTS AND METHODS: A prospective study was performed to evaluate the body composition of 16 elderly males (aged 63-96; median age 71) with prostate cancer scheduled for orchiectomy, one year before and after surgery. Body composition was measured by DEXA, and energy expenditure, fat and carbohydrate oxidation were measured by indirect calorimetry.

RESULTS: Body weight $(\mathrm{p}=0.01)$, lean mass $(\mathrm{p}=0.004)$, and lipid oxidation $(\mathrm{p}=0.001)$ decreased significantly. Carbohydrate oxidation $(\mathrm{p}=0.02), \mathrm{FSH}(\mathrm{p}=0.0001)$ and LH $(\mathrm{p}=0.0001)$ levels increased significantly. Changes in fat mass $(\mathrm{p}=0.06)$ and bone mineral density $(\mathrm{p}=0.48)$ were not significant.

CONCLUSIONS: After 12 months of androgen deprivation therapy, elderly men with metastatic prostate cancer exhibit a decline in lean body mass and lipid oxidation, together with increased carbohydrate oxidation.

KEYWORDS: Androgen deprivation; Metastatic prostate cancer; Hormonotherapy side effects; Lean body mass; Lipolysis regulation.

\section{INTRODUCTION}

The prostate is the site of two common diseases in aging men, benign prostatic hyperplasia and prostate cancer $(\mathrm{PCa})$. Epidemiological studies show that, in the United States, $\mathrm{PCa}$ accounts for $28.7 \%$ of new non-skin cancers and $12.7 \%$ of cancer-related deaths. ${ }^{1}$ Androgen deprivation therapy (ADT) retards PCa progression in $60 \%-80 \%$ of patients

Department of Geriatric and Gerontology, Department of Endocrinology and Metabolism and Department of Urology, Faculdade de Medicina da Universidade de São Paulo - São Paulo/SP, Brazil

Email: vitalita@uol.com.br

Tel: $\mathbf{5 5 3 0 8 8 . 7 5 9 7}$

Received for publication on May 12, 2009

Accepted for publication on May 25, 2009 but may cause cardiovascular complications and alterations in body composition, lipoprotein metabolism, and sexual function. In general, ADT may result in a decreased quality of life. Furthermore, studies in men demonstrate that low serum testosterone $(\mathrm{T})$ levels are associated with several cardiovascular risk factors, ${ }^{2,3}$ such as lower high density lipoprotein cholesterol, higher triglyceride concentrations, hyperinsulinemia, and increased abdominal adiposity. These factors are all characteristic of the metabolic insulin resistance syndrome. In addition, many patients treated with ADT experience rapid bone loss that increases the risk of debilitating osteoporotic fractures. ${ }^{4-6}$ Reports indicate that total and free levels of serum $\mathrm{T}$ decline in aging men and that abdominal visceral fat is inversely associated with $\mathrm{T}$ levels. Resting energy expenditure (REE), which accounts for 
$60 \%-70 \%$ of total daily energy expenditure, decreases with age, physical inactivity, sympathetic nervous system and endocrine status. ${ }^{7,8}$ To our knowledge, the effects of ADT on REE have not been fully explored in controlled trials. The goal of this prospective study was to determine the effects of ADT on body composition and resting metabolic rate in patients with metastatic $\mathrm{PCa}$.

\section{PATIENTS AND METHODS}

Sixteen men, aged 63 to 96 years (mean age 71), with untreated metastatic PCa were enrolled in this study.

Prior to orchiectomy, all patients were evaluated clinically and by laboratory analysis to establish a baseline. After a careful medical history had been taken from each patient, we assessed several exclusion criteria, namely, cognitive alterations, depression and emotional liability.

Laboratory examinations included tests of FSH-LH serum concentrations, and an evaluation of body mass index, fat/lean body mass, bone mineral density, carbohydrate/lipid oxidation, and resting energy expenditure.

Following orchiectomy, the same evaluation was carried out monthly and after 12 months, the period chosen for final analysis.

To evaluate body composition, all patients underwent densitometry testing (dual-energy $\mathrm{X}$ ray absorptiometry DEXA). ${ }^{9}$ The REE, fat and carbohydrate oxidation levels were measured using indirect calorimetry, with a DeltaTRAC Metabolic Monitor. ${ }^{10}$ Body composition analyses and indirect calorimetry were carried out at baseline and after 12 months following the orchiectomy procedure.

Written consent was obtained from all patients, and this protocol was approved by the Ethics Committee at our institution.

\section{Statistical analysis}

We used the non-parametric two-sided Wilcoxon t-test, and $\mathrm{p}<0.05$ was considered significant to appropriately compare time differences for each variable. ${ }^{11}$

\section{RESULTS}

Statistically significant differences in body composition pre and post orchiectomy were seen in terms of weight, body mass index (BMI) and lean body mass (LBM). Total fat body mass (FBM) exhibited a tendency to increase but failed to reach significance. No significant changes were observed in bone mineral density (BMD) and REE, but we identified a statistically significant change in terms of increased carbohydrate oxidation (CHOox) and a decrease in lipid oxidation (LIPIDox). These results are listed in Table 1.

\section{DISCUSSION}

Aging is associated with sarcopenia (loss of muscle mass), with an average $12 \mathrm{~kg}$ loss of LBM between the ages of 25 and 70 years and an increase in FBM of 18\%-36\% during the same period. ${ }^{2}$ Testosterone levels exhibit a positive correlation with LBM and a negative correlation with FBM. This has led to the hypothesis that ADT may help mitigate age-related alterations in body composition.

Our study reports two major findings: 1) ADT was associated with decreased body weight and with decreased LBM; 2) ADT led to increased CHOox and decreased LIPIDox.

Androgens modulate body composition, including lipid and protein metabolism. ${ }^{12}$ Smith et al, ${ }^{13}$ Galvão et al,,${ }^{14}$ Levy et $a 1,{ }^{15}$ and Van Londen et $\mathrm{al}^{16}$ observed significant

Table 1 - Mean values of variables at baseline and 12 months after orchiectomy

\begin{tabular}{|c|c|c|c|c|}
\hline Variables & Basal (mean $\pm \mathrm{SD})$ & 12 months $($ mean $\pm \mathrm{SD})$ & $\Delta \%($ mean $\pm \mathrm{SD})$ & $\mathrm{p}$ \\
\hline Weight (kg) & $72.5 \pm 11.6$ & $70.2 \pm 11.5$ & $-3.4 \pm 1.3$ & 0.01 \\
\hline Body mass index $\left(\mathrm{kg} / \mathrm{m}^{2}\right)$ & $26.0 \pm 3.6$ & $25.1 \pm 3.8$ & $-3.0 \pm 1.4$ & 0.02 \\
\hline Fat body mass (kg) & $27.5 \pm 10.9$ & $34.7 \pm 14.9$ & $36.0 \pm 15.1$ & 0.06 \\
\hline Lean body mass (kg) & $39.8 \pm 9.5$ & $28.0 \pm 14.3$ & $-30.2 \pm 8.0$ & 0.004 \\
\hline Bone mineral density $\left(\mathrm{g} / \mathrm{cm}^{2}\right)$ & $1.990 \pm 0.461$ & $1.997 \pm 0.432$ & $2.0 \pm 4.7$ & 0.48 \\
\hline Carbohydrate oxidation (mg/min) & $56.7 \pm 20.7$ & $70.1 \pm 14.7$ & $52.6 \pm 28.0$ & 0.02 \\
\hline Lipid oxidation (mg/min) & $43.2 \pm 20.6$ & $30.3 \pm 14.0$ & $-4.1 \pm 26.9$ & 0.01 \\
\hline Resting energy expenditure (kcal/24h) & $1.177 \pm 237.7$ & $1.072 \pm 323.5$ & $-7.1 \pm 7.3$ & 0.26 \\
\hline LH (IU/L) & $12.4 \pm 3.3$ & $54.5 \pm 6.7$ & $735 \pm 17.7$ & 0.0001 \\
\hline FSH (IU/L) & $6.9 \pm 1.6$ & $34.8 \pm 4.4$ & $990 \pm 302.5$ & 0.0001 \\
\hline
\end{tabular}


changes in metabolic and body composition parameters after 6 months of induced hypogonadism in all patients. These studies included 22, 72, 35 and 81 men, respectively. The researchers observed a significant increase in FBM (20.2 \pm 9.4 to $21.9 \pm 9.6 \mathrm{~kg},{ }^{13} 13.8 \pm 2.3 \%,{ }^{14} 1.17 \pm 2.3 \%,{ }^{15}$ and $2167.15 \mathrm{~g},{ }^{16}$ respectively) and a significant decrease in $\mathrm{LBM}\left(63.2 \pm 8.0\right.$ to $62.3 \pm 5.4 \mathrm{Kg},{ }^{13}-2.4 \pm 0.4 \%,{ }^{14}$ $-1.15 \pm 2.20 \%{ }^{15}$ and $-1785.81 \mathrm{~g},{ }^{16}$ respectively) with no significant changes in total body weight, lipid readings or glucose metabolism.

They also reported a positive correlation between the changes in FBM and insulin concentrations ( $r=0.56$; $\mathrm{p}=0.013$ ). These results are in agreement with other studies that demonstrated a relationship between $\mathrm{T}$ and abnormalities in carbohydrate and lipid metabolism. ${ }^{17}$ In healthy male populations, low $\mathrm{T}$ concentrations are negatively correlated with the degree of central abdominal obesity. In hypogonadal males, there is a tendency toward increased visceral adiposity and reduced muscle mass that can be reversed by androgen replacement. ${ }^{18}$ The underlying mechanisms for these observations are not well defined, but androgen receptors are known to be present on visceral adipocytes. It is likely that $\mathrm{T}$ is directly involved in the mobilization of free fatty acids. ${ }^{19}$

We observed significant changes in metabolic and body composition in our patients after ADT. We identified significant decreases in total body weight, BMI and LBM $\left(2.5 \mathrm{~kg}, \mathrm{p}=0.01 ;-0.8 \mathrm{~kg} / \mathrm{cm}^{2}, \mathrm{p}=0.02,-11.7 \mathrm{~kg}, \mathrm{p}=0.002\right.$, respectively). FBM was found to increase $(7.15 \mathrm{~kg}, \mathrm{p}=$ $0.06)$ with no significant change in bone mineral density (BMG). There were no changes in REE, but we did identify a significant increase in CHOox and a decrease in LIPIDox $(52.62 \%,-4.10 \%$ respectively). In one study, suppression of T levels after 10 weeks of GnRH agonist administration was found to reduce REE in young men. In this study, researchers were unable to determine whether the effect was directly mediated by a reduction in $\mathrm{T}$ levels or if it was due to a subsequent reduction in $\mathrm{T}$ aromatization to estrogen. ${ }^{20}$ We were unable to show alterations in REE in our study, possibly due to the size of our study sample. The altered concentrations of gonadotropins following orchiectomy may be linked with the effects of this procedure on the pituitary gland. It is possible that other pituitary hormones (growth hormone) are also affected. This in turn may contribute to the observed changes in body composition. It is important to consider that ADT not only acts on PCa but also affects metabolism, including hematogenesis, bone, fat, protein, and sarcho-metabolism. Despite PCa being one of the leading causes of death, a substantial proportion of aging patients die of unrelated causes that are due to comorbidities, often in the context of metabolic syndrome.

The present study has several strengths and some limitations. To our knowledge, this is the first prospective study to examine changes in body composition, resting energy expenditure, and consequences involving the oxidation of carbohydrates and lipids in the context of ADT.

A study on a larger group of patients would be of great interest once a limited number of patients included from only one centre may be considered a limitation in this study.

\section{CONCLUSION}

After 12 months of androgen deprivation therapy, elderly males with metastatic prostate cancer exhibit declines in lean body mass and lipid oxidation, together with an increase in carbohydrate oxidation.

\section{REFERENCES}

1. Landis S, Murray T, Bolden S, Wingo PA. Cancer statistics. CA Cancer J Clin. 1999;49:8-31.

2. Nishiyama T, Ishizaki F, Anraku T, Shimura H, Takahashi K. The influence of androgen deprivation therapy on metabolism in patients with prostate cancer. J Clin Endocrinol Metab. 2005;90:657-60.

3. Barrett-Connor E, Khaw KT. Endogenous sex hormones and cardiovascular disease in men. Circulation. 1998;78:539-45.

4. Daniell HW. Osteoporosis due to androgen deprivation therapy in men with prostate cancer. Urology 2001;58(2 Suppl 1):101-7.

5. Eastham J. Bone health in men receiving androgen deprivation therapy for prostate cancer. J Urol. 2007;177:17-24.

6. Israeli R, Ryan C, Jung L. Managing bone loss in men with locally advanced prostate cancer receiving androgen deprivation therapy. $\mathrm{J}$ Urol. 2008;179:414-23.
7. Harman SM, Metter EJ, Tobin JD, Pearson J, Blackman MR; Baltimore Longitudinal Study of Aging. Longitudinal effects of aging on serum total and free testosterone levels in healthy men. Baltimore Longitudinal Study of Aging. J Clin Endocrinol Metab. 2001;86:724-31.

8. Roubenoff R, Hughes VA, Dallal GE, Nelson ME, Morganti C, Kehayias $\mathrm{JJ}$, et al. The effect of gender and body composition on the apparent decline in lean-mass adjusted resting metabolic rate with age. J Gerontol A Biol Sci Med Sci. 2000;55: M757-60.

9. Haarbo J, Gotfredsen A, Hassager C, Christiansen C. Validation of body composition measurement by dual energy X-ray absorptiometry (DEXA). Clin Physiol. 1991;11:331-41.

10. Ferrannini E. The theoretical bases of indirect calorimetry: a review. Metabolism. 1988;37:287-301.

11. Altman DG. Practical statistics for medical research. London: Chapman \& Hall; 1991. p. 213-5. 
12. Smith MR, Finkelstein JS, McGovern FJ, Zietman AL, Fallon MA, Schoenfeld DA, et al. Changes in body composition during androgen deprivation therapy for prostate cancer. J Clin Endocrinol Metab. 2002;87:599-603.

13. Smith JC, Bennett S, Evans LM, Kynaston HG, Parmar M, Mason MD, et al. The effects of induced Hypogonadism on arterial stiffness, body composition, and metabolic parameters in males with prostate cancer. J Clin Endocrinol Metab. 2001;86:4261-7.

14. Galvão D, Spry N, Taaffe D, Newton R, Stanley J,Shannon T, et al Changes in muscle, fat and bone mass after 36 weeks of maximal androgen blockade for prostate cancer. BJU Int. 2008;102:44-7.

15. Levy M, Perera S, van Londen G, Nelson J, Clay C, Greenspan S Physical function changes in prostate cancer patients on androgen deprivation therapy: A 2-year prospective study.Urology. 2008;71:735-9.

16. van Londen G, Levy Matthew, Perera S, Nelson J, Greenspan S. Body composition changes during androgen deprivation therapy for prostate cancer: A 2-year prospective study.Crit Rev Oncol Hematol. 2008;68:172-7.
17. Haffner SM, Karhapaa P, Mykkanen L, Laakso M. Insulin resistance, body fat distribution, and sex hormones in men. Diabetes. 1994;43:2129 .

18. Katznelson L, Finkelstein JS, Schoenfeld DA, Rosenthal DI, Anderson EJ, Klibanski A. Increase in bone density and lean body mass during testosterone administration in men with acquired hypogonadism. J Clin Endocrinol Metab. 1996;81:4358-65.

19. Xu X, De Pergola G, Bjorntorp P. The effects of androgens on the regulation of lipolysis in adipose precursor cells. Endocrinology. 1990;126:1229-34.

20. Mauras N, Hayes V, Welch S, Rini A, Helgeson K, Dokler M, et al. Testosterone deficiency in young men: marked alterations in whole body protein kinetics, strength, and adiposity. J Clin Endocrinol Metab. 1998;83:1886-92. 